\title{
Formoterol fumarate and roxithromycin effects on muscle mass in an animal model of cancer cachexia
}

\author{
RICHARD A. KENLEY ${ }^{1}$, MIKHAIL F. DENISSENKO ${ }^{2}$, ROBERT J. MULLIN ${ }^{3}$, \\ JENNIFER STORY ${ }^{3}$ and JONAS EKBLOM ${ }^{4}$ \\ ${ }^{1}$ Anaborex, Inc., 2223 Avenida De la Playa, Suite 300, La Jolla, CA 92037; ${ }^{2}$ Invitrogen, Inc., 1600 Faraday \\ Avenue, Carlsbad, CA 92008; ${ }^{3}$ Piedmont Research Center, 3300 Gateway Centre Boulevard, \\ Morrisville, NC 27560; ${ }^{4}$ The Releef Initiative, Glendale, CA 91208, USA
}

Received December 20, 2007; Accepted January 24, 2008

\begin{abstract}
Our study probed the effects of the B-2 adrenergic agonist, formoterol and the macrolide antibiotic, roxithromycin, on muscle wasting in a well-characterized animal model of cancer cachexia. Female Wistar rats were inoculated with Yoshida AH130 ascites hepatoma (AH) cells to induce rapid and severe cachexia as demonstrated by wet weight determinations of the hearts, gastrocnemius muscles and carcasses. The control animals received saline (vehicle) inoculations. The $\mathrm{AH}$-inoculated rats were treated once daily for four days by i.p. injection with a vehicle control, $1 \mathrm{mg} / \mathrm{kg}$ formoterol, 5 and $50 \mathrm{mg} / \mathrm{kg}$ roxithromycin or $1 \mathrm{mg} / \mathrm{kg}$ formoterol plus $5,25,40$ and $50 \mathrm{mg} / \mathrm{kg}$ roxithromycin. The saline-inoculated animals were treated by i.p. injection with vehicle control, $1 \mathrm{mg} / \mathrm{kg}$ formoterol, 5 and $40 \mathrm{mg} / \mathrm{kg}$ roxithromycin. As a result, formoterol alone reduced the loss of muscle mass in the AHinoculated rats by approximately one-half, consistent with literature reports. Roxithromycin alone at $5 \mathrm{mg} / \mathrm{kg}$ did not affect muscle mass in the $\mathrm{AH}$-inoculated rats. Roxithromycin given alone at $50 \mathrm{mg} / \mathrm{kg}$ reduced the loss of muscle mass in $\mathrm{AH}$-inoculated animals by approximately one-half. With respect to the antagonizing muscle loss, formoterol combined with either 5 or $25 \mathrm{mg} / \mathrm{kg}$ roxithromycin did not reach statistical significance versus formoterol alone, while formoterol plus either 40 or $50 \mathrm{mg} / \mathrm{kg}$ roxithromycin enhanced protection against muscle loss versus formoterol alone. The gastrocnemius weights in the $\mathrm{AH}$-inoculated rats treated with formoterol combined with $40 \mathrm{mg} / \mathrm{kg}$ roxithromycin were not significantly different from the muscle weights in the saline-inoculated controls. To sum up, formoterol and roxithromycin apparently exert anti-cachectic effects in an additive fashion and may offer the potential for combination therapy in cachexia.
\end{abstract}

Correspondence to: Dr Richard A. Kenley, Anaborex, Inc., 2223 Avenida De la Playa, Suite 300, La Jolla, CA 92037, USA

E-mail: rkenley@anaborex.com

Key words: formoterol, roxithromycin, AH130, rat, cachexia

\section{Introduction}

Patients with advanced malignancies frequently develop anorexia and cachexia (1-14). Anorexia, a medical term for appetite loss, includes a decreased sense of taste and smell for food, early satiety, a decreased sense of hunger and outright aversion to food. Catabolic wasting, or cachexia, is a syndrome characterized by the involuntary and progressive loss of fat and skeletal muscle, refractoriness of weight loss to an increased nutritional input, an elevated resting energy expenditure (REE), a decreased protein synthesis, an altered carbohydrate metabolism (increased Cori cycle activity), hypercatabolism of the muscle via elevated proteolysis and of the adipose tissue via lipolysis $(13,15)$. At least $5 \%$ of pre-illness body weight must have been lost before a patient is diagnosed with cachexia. Roughly half of all cancer patients experience some degree of catabolic wasting, with a higher occurrence seen in cases of malignancies of the lung, pancreas and gastrointestinal tract (16). The syndrome is found in patients with immunodeficiency disorders, such as AIDS, as well patients suffering from bacterial and parasitic diseases, rheumatoid arthritis and chronic diseases of the bowel, liver, kidneys, lungs and heart. Cachexia is often associated with anorexia and can manifest as a condition in aging or as a result of physical trauma and burn injuries. The cachexia syndrome diminishes the functional ability and quality of life of the patient, worsens the underlying condition, reduces tolerance to medications and is a major cause of death.

Despite the fact that cachexia is often associated with cancer, no consistent relationship has been demonstrated between the development of cachexia and tumor size, disease stage and the type or duration of the malignancy. Molecular mechanisms underlying the cancer anorexia and cachexia syndrome (CACS) are complex and incompletely understood. Elevated levels of pro-inflammatory cytokines (such as interleukin-6 and tumor necrosis factor alpha) and acute phase proteins (such as the C-reactive protein) are a host response to the malignancy and a trigger mechanism for metabolic abnormalities such as muscle hypercatabolism (17-21). The ATP-ubiquitin-dependent proteasome pathway of proteolysis is a well-accepted $(12,22-26)$ mechanism in cachexia. Numerous studies have demonstrated that ubiquitin and proteasomal 
Table I. Experimental design for rat ascites hepatoma (AH) studies with roxithromycin and formoterol treatment groups. ${ }^{\mathrm{a}}$

\begin{tabular}{|c|c|c|c|c|}
\hline \multirow[b]{2}{*}{ Experiment no. } & \multirow[b]{2}{*}{ Group no. } & \multirow[b]{2}{*}{ Inoculum } & \multicolumn{2}{|c|}{ Intraperitoneal dose $(\mathrm{mg} / \mathrm{kg})$} \\
\hline & & & Formoterol fumarate & Roxithromycin \\
\hline 1 & 1 & $\mathrm{AH}^{\mathrm{b}}$ & 0 & 0 \\
\hline 1 & 2 & Saline & 0 & 0 \\
\hline 1 & 3 & $\mathrm{AH}^{\mathrm{b}}$ & 1 & 0 \\
\hline 1 & 4 & $\mathrm{AH}^{\mathrm{b}}$ & 0 & 5 \\
\hline 2 & 5 & $\mathrm{AH}^{\mathrm{b}}$ & 0 & 0 \\
\hline 2 & 6 & Saline & 0 & 0 \\
\hline 2 & 7 & $\mathrm{AH}^{\mathrm{b}}$ & 1 & 0 \\
\hline 2 & 8 & $\mathrm{AH}^{\mathrm{b}}$ & 1 & 5 \\
\hline 2 & 9 & Saline & 0 & 5 \\
\hline 2 & 10 & Saline & 1 & 0 \\
\hline 3 & 11 & $\mathrm{AH}^{\mathrm{b}}$ & 0 & 0 \\
\hline 3 & 12 & Saline & 0 & 0 \\
\hline 3 & 13 & $\mathrm{AH}^{\mathrm{b}}$ & 1 & 0 \\
\hline 3 & 14 & $\mathrm{AH}^{\mathrm{b}}$ & 1 & 40 \\
\hline 3 & 15 & Saline & 0 & 40 \\
\hline 4 & 16 & $\mathrm{AH}^{\mathrm{b}}$ & 0 & 0 \\
\hline 4 & 17 & Saline & 0 & 0 \\
\hline 4 & 18 & $\mathrm{AH}^{\mathrm{b}}$ & 1 & 0 \\
\hline 4 & 19 & $\mathrm{AH}^{\mathrm{b}}$ & 1 & 25 \\
\hline 4 & 20 & $\mathrm{AH}^{\mathrm{b}}$ & 1 & 50 \\
\hline 4 & 21 & $\mathrm{AH}^{\mathrm{b}}$ & 0 & 50 \\
\hline
\end{tabular}

aTreatment Group = Inoculation type/vehicle, or treatment group = Inoculation type/ $\mathrm{F}(0) \mathrm{R}(0)$, where, inoculation type is either AH or saline; $\mathrm{F}$, formoterol fumarate; $\mathrm{R}$, roxithromycin and the parenthetical values are formoterol fumarate and roxithromycin doses (i.p. in $\mathrm{mg} / \mathrm{kg}$ ). b2.0x $10^{7}$ cells/animal.

mRNAs are overexpressed in cachectic animals (27-35) and patients (36-41).

Current methods for treating CACS have only a limited benefit at best. As summarized by Yavuzsen et al (1), examples of randomized controlled clinical trials that yielded negative, mixed or inconclusive results include trials with hydrazine sulfate, cyproheptadine, pentoxifylline, melatonin, erythropoietin with and without indomethacin, eicosapentaenoic acid, androgenic steroids, ghrelin, interferon and dronabinol. Of the drugs reviewed, only corticosteroids and progestins, demonstrated consistently positive results in the multiple randomized, and controlled clinical trials. In particular, the progesterone derivative, megestrol acetate, has been shown to increase appetite and weight (but not quality of life, survival or functional ability) in cancer cachexia patients. Evidence from clinical studies indicates that the increase in body weight observed during megestrol acetate therapy is indirect and is related to the appetite stimulation of the drug. There remains a need for better therapeutic options to help patients suffering from cachexia and anorexia. To investigate novel combination options of treating CACS based on the postulated molecular pathways, we selected two classes of existing drugs with specific molecular action profiles: macrolide antibiotics and ß-2 adrenergic agonists.

Illustrating the link between inflammation and CACS, Piffar et al (42) showed in a rat model of cancer cachexia that the non-steroidal anti-inflammatory drug naproxen reduced tumor growth and increased muscle mass, and that these beneficial effects were enhanced by the co-administration of the $3-2$ adrenergic agonist, clenbuterol. Macrolide antibiotics, structurally related to erythromycin, are also known to decrease the levels of pro-inflammatory cytokines and acute phase proteins (44-50). Specifically, roxithromycin bears apparent anti-inflammatory effects and has the ability to reduce the circulating levels of pro-inflammatory cytokines (51-55). The roxithromycin mechanism of action still remains the subject of investigation, but suppressing nuclear transcription factor $\kappa \mathrm{B}(\mathrm{NF} \kappa \mathrm{B})$ activity is an important factor $(56,57)$.

The $3-2$ adrenergic agonists exhibit anti-catabolic in addition to the main line bronchodilator activity (34,58-62). The $3-2$ agonists have recently been demonstrated (63) to increase lean body mass by increasing protein synthesis and by interfering with the ATP-dependent ubiquitin-proteasome pathway (notably, the two mechanisms underlying muscle 
Table II. The gravimetric data for rat AH Experiment 1.

\begin{tabular}{|c|c|c|c|c|c|c|c|c|c|c|}
\hline \multirow[t]{2}{*}{ Group } & \multirow[t]{2}{*}{ Inoculum } & \multicolumn{2}{|c|}{ Dose $(\mathrm{mg} / \mathrm{kg})^{\mathrm{a}}$} & \multirow[t]{2}{*}{$\mathrm{N}^{\mathrm{b}}$} & \multicolumn{2}{|c|}{ Heart $^{\mathrm{c}}$} & \multicolumn{2}{|c|}{ Gastrocnemius $^{\mathrm{c}}$} & \multicolumn{2}{|c|}{ Carcass $^{\mathrm{c}, \mathrm{d}}$} \\
\hline & & $\mathrm{F}$ & $\mathrm{R}$ & & Mean & SEM & Mean & SEM & Mean & SEM \\
\hline 1 & $\mathrm{AH}$ & 0 & 0 & 7 & 0.320 & 0.008 & 0.503 & 0.005 & 93.96 & 0.70 \\
\hline 2 & Saline & 0 & 0 & 7 & 0.359 & 0.010 & 0.588 & 0.007 & 96.26 & 0.75 \\
\hline 3 & $\mathrm{AH}$ & 1 & 0 & 7 & 0.337 & 0.009 & 0.551 & 0.012 & 95.35 & 0.86 \\
\hline 4 & $\mathrm{AH}$ & 0 & 5 & 9 & 0.320 & 0.009 & 0.493 & 0.004 & 94.35 & 0.71 \\
\hline
\end{tabular}

${ }^{\mathrm{a}} \mathrm{F}$, formoterol fumarate and R, roxithromycin. ${ }^{\mathrm{b}}$ The number of evaluated animals. Animals that accumulated $<1 \mathrm{ml}$ of ascites were not considered in the analysis. ${ }^{\mathrm{c} S}$ Sample weights $(\mathrm{g})$ normalized to $100 \mathrm{~g}$ of Day 5 total body weight. ${ }^{\mathrm{d}}$ Carcass weights after removal of the heart, gastrocnemius and ascites.

Table III. Statistical comparisons for Experiment 1.

\begin{tabular}{lcccc}
\hline $\begin{array}{l}\text { Comparison } \\
\text { (Group vs. Group) }\end{array}$ & Heart & Gastrocnemius & Carcass $^{\mathrm{a}}$ \\
\hline 1 & 2 & $\mathrm{~ns}$ & $\mathrm{p}<0.001$ & $\mathrm{~ns}$ \\
1 & 3 & $\mathrm{~ns}$ & $\mathrm{p}<0.001$ & $\mathrm{~ns}$ \\
1 & 4 & $\mathrm{~ns}$ & $\mathrm{~ns}$ & $\mathrm{~ns}$ \\
2 & 3 & $\mathrm{~ns}$ & $\mathrm{p}<0.05$ & $\mathrm{~ns}$ \\
2 & 4 & $\mathrm{p}<0.05$ & $\mathrm{p}<0.001$ & $\mathrm{~ns}$ \\
3 & 4 & $\mathrm{~ns}$ & $\mathrm{p}<0.001$ & $\mathrm{~ns}$ \\
\hline
\end{tabular}

${ }^{a}$ Carcass weights after removal of the heart, gastrocnemius and ascites; ns, not significant.

loss in cachexia, vide supra). Of the approved $\beta$ - 2 adrenergic agonists, formoterol is known to be highly potent, selective and long-acting.

Accordingly, we have undertaken to study these drugs individually and in combination for the potential synergistic effect in antagonizing cachexia. We have chosen the rat ascites hepatoma model (30-34) as the system to probe the effects of the drugs and their combinations. In rats inoculated with Yoshida AH130 ascites hepatoma (AH) cells, the onset of severe cachexia is very rapid, and B-2 agonists (including formoterol) have previously been shown to antagonize the developed syndrome.

We therefore examined the effects of formoterol and roxithromycin, given individually and in combination, on the hallmarks of cachexia in the rat AH model. The objectives of the investigation were to: 1$)$ reproduce the reported effects of formoterol in the rat $\mathrm{AH}$ model, 2) assess the anti-cachectic activity of roxithromycin and 3) probe the potential for synergy when roxithromycin and formoterol are co-administered.

\section{Materials and methods}

Animals. The female Wistar rats (Charles River) were 5-6 weeks old, with a body weight of 150-225 g, on day zero (D0) of the study. The animals were fed ad libitum water (reverse osmosis, 1 ppm Cl) and a NIH 31 Modified and Irradiated Lab Diet $^{\circledR}$ consisting of $18.0 \%$ crude protein, $5.0 \%$ crude fat and $5.0 \%$ crude fiber. The rats were housed on irradiated Alpha$\mathrm{dri}^{\circledR}$ bed-o-cobs ${ }^{\circledR}$ laboratory animal bedding in static microisolators on a 12 -h light cycle at $21-22^{\circ} \mathrm{C}\left(70-72^{\circ} \mathrm{F}\right)$ and 40 $60 \%$ humidity. This study specifically complied with the recommendations of the guide for the care and use of laboratory animals with respect to restraint, husbandry, surgical procedures, feed and fluid regulation and veterinary care.

Tumor/saline inoculation. Yoshida AH130 rat ascites hepatoma cells (National Cancer Institute Division of Cancer Treatment and Diagnosis, Catalog page 510, 2003) were propagated in vivo using female Wistar rats. The AH cells used for implantation were harvested from the donor animal ascites fluid during the log phase growth and re-suspended in phosphate-buffered saline at $2 \times 10^{7}$ cells $/ \mathrm{ml}$. On D0, the animals in the test groups each received either an intraperitoneal (i.p.) injection of $1.0 \mathrm{ml}$ of the cell suspension (inoculum, AH) or sterile saline solution (inoculum, saline).

Test articles. Formoterol fumarate dihydrate (CAS 18381430-4) was supplied by Taizhou Candorly, Beijing, China. Roxithromycin (CAS 80214-83-1) was supplied by Zhejiang Zhenyuan, Shaoxing, China. Formoterol fumarate $(0.2 \mathrm{mg} / \mathrm{ml})$ and roxithromycin $(2.0 \mathrm{mg} / \mathrm{ml})$ were formulated in $20 \mathrm{mM}$ citrate, $\mathrm{pH} 5.5$ and $4.5 \%$ mannitol in water using USP/NF grade materials. The formoterol and roxithromycin solutions were stored at $4^{\circ} \mathrm{C}$.

Treatment regimen. All of the test and control articles were administered once daily for four days, starting on D1 with formoterol (nominal $1 \mathrm{ml}$ per rat, adjusted for actual D0 body weight) and roxithromycin (nominal $0.5 \mathrm{ml}$ ) solutions and matching vehicle control solutions by i.p. injection.

Measurements. The total body weight was recorded for each animal on D1-D5. After animals were euthanized on Day 5, the heart and the two gastrocnemius muscles were excised and individually weighed, and the carcass was re-weighed. Then, all of the fluid was withdrawn from the peritoneal cavity, and the residual carcass weight was recorded again. Throughout, the 'carcass' weight refers to the residual carcass 
Table IV. The gravimetric data for rat AH Experiment 2.

\begin{tabular}{|c|c|c|c|c|c|c|c|c|c|c|}
\hline \multirow[t]{2}{*}{ Group } & \multirow[t]{2}{*}{ Inoculum } & \multicolumn{2}{|c|}{ Dose $(\mathrm{mg} / \mathrm{kg})^{\mathrm{a}}$} & \multirow[t]{2}{*}{$\mathrm{N}$} & \multicolumn{2}{|c|}{ Heart $^{\mathrm{b}}$} & \multicolumn{2}{|c|}{ Gastrocnemius $^{\mathrm{b}}$} & \multicolumn{2}{|c|}{ Carcass $^{\mathrm{b}, \mathrm{c}}$} \\
\hline & & $\mathrm{F}$ & $\mathrm{R}$ & & Mean & SEM & Mean & SEM & Mean & SEM \\
\hline 5 & $\mathrm{AH}^{\mathrm{a}}$ & 0 & 0 & 10 & 0.349 & 0.0060 & 0.487 & 0.0090 & 92.5 & 0.91 \\
\hline 6 & Saline & 0 & 0 & 10 & 0.398 & 0.0080 & 0.565 & 0.0100 & 98.2 & 0.27 \\
\hline 7 & $\mathrm{AH}^{\mathrm{a}}$ & 1 & 0 & 10 & 0.348 & 0.0090 & 0.499 & 0.0050 & 89.7 & 0.53 \\
\hline 8 & $\mathrm{AH}^{\mathrm{a}}$ & 1 & 5 & 10 & 0.358 & 0.0100 & 0.514 & 0.0090 & 90.7 & 0.83 \\
\hline 9 & Saline & 0 & 5 & 10 & 0.390 & 0.0110 & 0.575 & 0.0070 & 97.6 & 0.48 \\
\hline 10 & $\mathrm{AH}^{\mathrm{a}}$ & 1 & 0 & 7 & 0.410 & 0.0100 & 0.613 & 0.0080 & 97.6 & 0.26 \\
\hline
\end{tabular}

${ }^{\mathrm{a}} \mathrm{F}$, formoterol fumarate and $\mathrm{R}$, roxithromycin. ${ }^{\mathrm{b}}$ Sample weight normalized to $100 \mathrm{~g}$ of Day 5 total body weight. ${ }^{\mathrm{c}}$ Carcass weights after removal of the heart, gastrocnemius and ascites.

after removal of the heart, gastrocnemius and ascites. Tissue weights were determined on a calibrated analytical balance (readable and repeatable to $0.1 \mathrm{mg}$ ).

Data analyses. After all of the weights were recorded, the weights of the heart, each gastrocnemius muscle and residual carcass, were normalized to a Day 5 body weight of 100 g. i.e. they were expressed as fractions of the total body weight on Day 5. In some of the analyses, the mean gastrocnemius weights in the test groups within an Experiment were normalized to the mean gastrocnemius weight of the salineinoculated, vehicle-treated group within the same Experiment. This normalization permitted the comparison of treatment groups between Experiments. The significance of differences among the means of the normalized tissue or body weight values for the various treatment groups was determined by analysis of variance (ANOVA). When the means differed significantly, Tukey's multiple comparison test was employed to determine whether any group mean differed significantly from another. The two-tailed statistical analyses were conducted at a significance level of $\mathrm{p}=0.05$, utilizing the Prism 3.03 (GraphPad) for Windows. For the AH-inoculated groups (in Experiment 1 only), when an animal indicated $<1.0 \mathrm{ml}$ of ascites fluid, engraftment failure was assumed and such failures were excluded from statistical analysis.

\section{Results}

Study design. In total, four experiments were undertaken to determine the effects of various treatment options. Table I shows the study design and drug dosing levels for the four experiments. In each Experiment, three animal groups served as controls, namely the saline-inoculated/vehicle-treated, AH-inoculated/vehicle-treated and AH-inoculated/Formoterol (1 $\mathrm{mg} / \mathrm{kg}$ )-treated groups. The treatment groups have been designated using the following conventions:

Treatment group = Inoculation type/vehicle, or

Treatment group $=$ Inoculation type $/ \mathrm{F}(0) \mathrm{R}(0)$

where, Inoculation type is either $\mathrm{AH}$ or saline, $\mathrm{F}$ is formoterol fumarate, $\mathrm{R}$ is roxithromycin and the parenthetical values are formoterol fumarate and roxithromycin doses (i.p. in $\mathrm{mg} / \mathrm{kg}$ ).
Table V. Statistical comparisons for Experiment 2.

\begin{tabular}{lcccc}
\hline $\begin{array}{l}\text { Comparison } \\
\text { (Group vs. Group) }\end{array}$ & Heart & Gastrocnemius & Carcass $^{\mathrm{a}}$ \\
\hline 5 & 6 & $\mathrm{p}<0.05$ & $\mathrm{p}<0.001$ & $\mathrm{p}<0.001$ \\
7 & 6 & $\mathrm{p}<0.05$ & $\mathrm{p}<0.001$ & $\mathrm{p}<0.001$ \\
8 & 6 & $\mathrm{~ns}$ & $\mathrm{p}<0.05$ & $\mathrm{p}<0.001$ \\
9 & 6 & $\mathrm{~ns}$ & $\mathrm{~ns}$ & $\mathrm{~ns}$ \\
10 & 6 & $\mathrm{~ns}$ & $\mathrm{~ns}$ & $\mathrm{~ns}$ \\
5 & 7 & $\mathrm{~ns}$ & $\mathrm{~ns}$ & $\mathrm{~ns}$ \\
5 & 8 & $\mathrm{~ns}$ & $\mathrm{~ns}$ & $\mathrm{~ns}$ \\
7 & 8 & $\mathrm{~ns}$ & $\mathrm{~ns}$ & $\mathrm{~ns}$ \\
\hline
\end{tabular}

${ }^{a}$ Carcass weights after removal of the heart, gastrocnemius and ascites; ns, not significant.

Experiment 1. Table II shows the data for Experiment 1 and Table III shows the results of the ANOVA analysis. In Experiment 1, gastrocnemius muscle loss was observed to be significantly greater for the $\mathrm{AH} /$ vehicle group than for the saline/vehicle group (1 vs. 2), confirming the highly cachectic nature of the $\mathrm{AH}$ model. Animals in the $\mathrm{AH} / \mathrm{F}(1) \mathrm{R}(0)$ group lost significantly less gastrocnemius muscle than animals in the $\mathrm{AH} /$ vehicle group (3 vs. 1). Animals in the $\mathrm{AH} / \mathrm{F}(0) \mathrm{R}(5)$ group lost approximately the same amount of gastrocnemius muscle as those in the AH/vehicle (4 vs. 1). The trends documented for gastrocnemius muscle weight changes in the various treatment groups roughly paralleled those observed for the heart and carcass weights (see Table II), indicating that the effects of the $\mathrm{AH}$ inoculation and treatments were general and not limited to the gastrocnemius muscle.

Experiment 2. Table IV shows data for Experiment 2 and Table $\mathrm{V}$ shows the results of the ANOVA analysis. In Experiment 2, the gastrocnemius weights for animals in the $\mathrm{AH} / \mathrm{F}(1) \mathrm{R}(5)$ group were not statistically significantly different from the muscle weights for animals in the $\mathrm{AH} / \mathrm{F}(1) \mathrm{R}(0)$ group (8 vs. 7$)$. Rats in the saline/F(0)R(5) group 
Table VI. The gravimetric data for rat AH Experiment 3.

\begin{tabular}{|c|c|c|c|c|c|c|c|c|c|c|}
\hline \multirow[t]{2}{*}{ Group } & \multirow[t]{2}{*}{ Inoculum } & \multicolumn{2}{|c|}{ Dose $(\mathrm{mg} / \mathrm{kg})^{\mathrm{a}}$} & \multirow[t]{2}{*}{$\mathrm{N}$} & \multicolumn{2}{|c|}{ Heart $^{\mathrm{b}}$} & \multicolumn{2}{|c|}{ Gastrocnemius $^{\mathrm{b}}$} & \multicolumn{2}{|c|}{ Carcass $^{\mathrm{b}, \mathrm{c}}$} \\
\hline & & $\mathrm{F}$ & $\mathrm{R}$ & & Mean & SEM & Mean & SEM & Mean & SEM \\
\hline 11 & $\mathrm{AH}$ & 0 & 0 & 10 & 0.341 & 0.0070 & 0.431 & 0.0040 & 93.6 & 0.52 \\
\hline 12 & Saline & 0 & 0 & 10 & 0.417 & 0.0120 & 0.536 & 0.0060 & 95.2 & 0.83 \\
\hline 13 & $\mathrm{AH}$ & 1 & 0 & 10 & 0.376 & 0.0140 & 0.489 & 0.0090 & 93.1 & 0.69 \\
\hline 14 & $\mathrm{AH}$ & 1 & 40 & 10 & 0.350 & 0.0360 & 0.528 & 0.0100 & 95.9 & 0.58 \\
\hline 15 & Saline & 0 & 40 & 10 & 0.400 & 0.0070 & 0.529 & 0.0080 & 96.5 & 0.52 \\
\hline
\end{tabular}

${ }^{\mathrm{a}} \mathrm{F}$, formoterol fumarate and R, roxithromycin. ${ }^{\mathrm{b}}$ Sample weights normalized to $100 \mathrm{~g}$ of Day 5 total body weight. ${ }^{\mathrm{c}}$ Carcass weights after removal of the heart, gastrocnemius and ascites.

Table VII. Statistical comparisons for Experiment 3.

\begin{tabular}{lcccc}
\hline Comparison (Group vs. Group) & Heart & Gastrocnemius & Carcass $^{\mathrm{a}}$ \\
\hline 11 & 12 & $\mathrm{p}<0.001$ & $\mathrm{p}<0.001$ & $\mathrm{~ns}$ \\
11 & 13 & $\mathrm{~ns}$ & $\mathrm{p}<0.001$ & $\mathrm{~ns}$ \\
11 & 14 & $\mathrm{~ns}$ & $\mathrm{p}<0.001$ & $\mathrm{~ns}$ \\
11 & 15 & not compared & $\mathrm{p}<0.05$ & $\mathrm{not}$ compared \\
12 & 13 & $\mathrm{~ns}$ & $\mathrm{~ns}$ & $\mathrm{~ns}$ \\
12 & 14 & $\mathrm{~ns}$ & $\mathrm{~ns}$ \\
12 & 15 & $\mathrm{~ns}$ & $\mathrm{p}<0.05$ & $\mathrm{p}<0.05$ \\
13 & 14 & $\mathrm{~ns}$ & not compared & not compared \\
13 & 15 & not compared & not compared & not compared \\
14 & 15 & not compared & & \\
\hline
\end{tabular}

${ }^{\mathrm{a}}$ Carcass weights after removal of the heart, gastrocnemius and ascites; ns, not significant.

Table VIII. Gravimetric data for rat AH Experiment $4^{\mathrm{d}}$.

\begin{tabular}{|c|c|c|c|c|c|c|c|c|c|}
\hline \multirow[t]{2}{*}{ Group } & \multirow[t]{2}{*}{ Inoculum } & \multicolumn{2}{|c|}{ Dose $(\mathrm{mg} / \mathrm{kg})^{\mathrm{a}}$} & \multicolumn{2}{|c|}{ Heart $^{\mathrm{b}}$} & \multicolumn{2}{|c|}{ Gastrocnemius } & \multicolumn{2}{|c|}{ Carcass $^{\mathrm{b}, \mathrm{c}}$} \\
\hline & & $\mathrm{F}$ & $\mathrm{R}$ & Mean & SEM & Mean & SEM & Mean & SEM \\
\hline 16 & $\mathrm{AH}^{\mathrm{a}}$ & 0 & 0 & 0.323 & 0.0080 & 0.453 & 0.0051 & 90.6 & 0.80 \\
\hline 17 & Saline & 0 & 0 & 0.405 & 0.0069 & 0.556 & 0.0080 & 96.5 & 0.76 \\
\hline 18 & $\mathrm{AH}^{\mathrm{a}}$ & 1 & 0 & 0.367 & 0.0160 & 0.502 & 0.0120 & 92.2 & 0.70 \\
\hline 19 & $\mathrm{AH}^{\mathrm{a}}$ & 1 & 25 & 0.344 & 0.0085 & 0.477 & 0.0080 & 91.4 & 0.64 \\
\hline 20 & $\mathrm{AH}^{\mathrm{a}}$ & 1 & 50 & 0.373 & 0.0106 & 0.520 & 0.0097 & 94.8 & 0.72 \\
\hline 21 & $\mathrm{AH}^{\mathrm{a}}$ & 0 & 50 & 0.338 & 0.0130 & 0.500 & 0.0092 & 94.1 & 0.61 \\
\hline
\end{tabular}

${ }^{\mathrm{a}} \mathrm{F}$, formoterol fumarate and $\mathrm{R}$, roxithromycin. ${ }^{\mathrm{b}}$ Sample weight normalized to $100 \mathrm{~g}$ of Day 5 total body weight. ${ }^{\mathrm{C}} \mathrm{Carcass}$ weights after removal of the heart, gastrocnemius and ascites. ${ }^{\mathrm{d}} \mathrm{N}=10$ animals per group. ${ }^{\mathrm{e}} \mathrm{N}=6$ animals per group.

had approximately the same gastrocnemius muscle weights as rats in the saline/vehicle group (9 vs 6). Animals in the saline/F(1)R(0) group had higher (but not statistically signifi- cantly different) gastrocnemius muscle weights than animals in the saline/vehicle group (10 vs. 6), consistent with the known (30) anti-catabolic effects of formoterol fumarate in rats. 


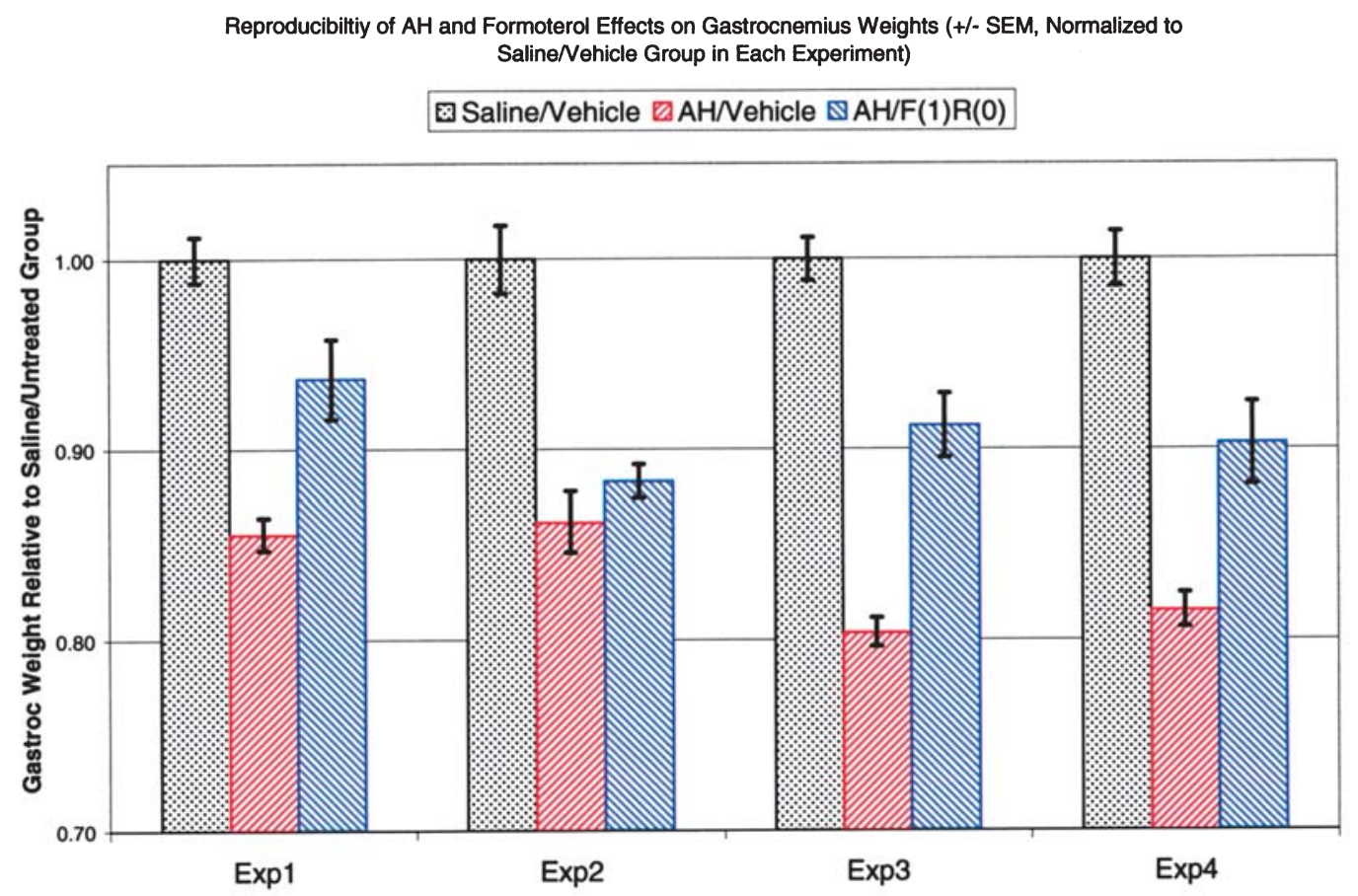

Figure 1. Reproducibility of the formoterol effect on gastrocnemius muscle weights in Experiments 1-4.

Table IX. Statistical comparisons for Experiment 4.

\begin{tabular}{lcccc}
\hline \multirow{2}{*}{ Comparison } & \multicolumn{3}{c}{ Significance for tissue } \\
\cline { 3 - 5 } (Group vs. Group) & Heart & Gastrocnemius & Carcass ${ }^{\mathrm{a}}$ \\
\hline 16 & 17 & $\mathrm{p}<0.05$ & $\mathrm{p}<0.05$ & $\mathrm{p}<0.05$ \\
16 & 18 & $\mathrm{~ns}$ & $\mathrm{p}<0.05$ & $\mathrm{~ns}$ \\
16 & 19 & $\mathrm{~ns}$ & $\mathrm{~ns}$ & $\mathrm{~ns}$ \\
16 & 20 & $\mathrm{p}<0.05$ & $\mathrm{p}<0.05$ & $\mathrm{p}<0.05$ \\
16 & 21 & $\mathrm{~ns}$ & $\mathrm{p}<0.05$ & $\mathrm{p}<0.05$ \\
17 & 18 & $\mathrm{~ns}$ & $\mathrm{p}<0.05$ & $\mathrm{p}<0.05$ \\
17 & 19 & $\mathrm{p}<0.05$ & $\mathrm{p}<0.05$ & $\mathrm{p}<0.05$ \\
17 & 20 & $\mathrm{~ns}$ & $\mathrm{~ns}$ & $\mathrm{~ns}$ \\
17 & 21 & $\mathrm{p}<0.05$ & $\mathrm{p}<0.05$ & $\mathrm{~ns}$ \\
18 & 19 & $\mathrm{~ns}$ & $\mathrm{~ns}$ & $\mathrm{~ns}$ \\
18 & 20 & $\mathrm{~ns}$ & $\mathrm{~ns}$ & $\mathrm{~ns}$ \\
18 & 21 & $\mathrm{~ns}$ & $\mathrm{~ns}$ & $\mathrm{~ns}$ \\
19 & 20 & $\mathrm{~ns}$ & $\mathrm{p}<0.05$ & $\mathrm{p}<0.05$ \\
19 & 21 & $\mathrm{~ns}$ & $\mathrm{~ns}$ & $\mathrm{~ns}$ \\
20 & 21 & $\mathrm{~ns}$ & $\mathrm{~ns}$ & $\mathrm{~ns}$ \\
\hline
\end{tabular}

${ }^{a}$ Carcass weights after removal of the heart, gastrocnemius and ascites; ns, not significant.

Experiment 3. Table VI shows the data for Experiment 3 and Table VII shows the results of the ANOVA analysis. In Experiment 3, rats in the $\mathrm{AH} / \mathrm{F}(1) \mathrm{R}(40)$ group had much greater gastrocnemius muscle weights than rats in the
$\mathrm{AH} / \mathrm{F}(1) \mathrm{R}(0)$ group (14 vs. 13). The gastrocnemius muscle weight differences between Groups 14 and 13 were found to be statistically significant. For animals in the AH/ F(1)R(40) group, the gastrocnemius weights were not statistically significantly different from the muscle weights for animals in the saline/vehicle control group (14 vs. 12). Gastrocnemius muscle weights were also not statistically significantly different in the saline/F(0)R(40) group compared with the saline/ vehicle control group (15 vs. 12).

Experiment 4. Table VIII shows the data for Experiment 4 and Table IX shows the results of the ANOVA analysis. In Experiment 4, the gastrocnemius net muscle weights for rats in the $\mathrm{AH} / \mathrm{F}(1) \mathrm{R}(25)$ group were not statistically significantly different from those for rats in the $\mathrm{AH} / \mathrm{F}(1) \mathrm{R}(0)$ group (19 vs. $18)$. For animals in the $\mathrm{AH} / \mathrm{F}(1) \mathrm{R}(50)$ group, gastrocnemius weights were higher than those for animals in the $\mathrm{AH} / \mathrm{F}(1) \mathrm{R}(0)$ group (20 vs. 18), but the differences were not statistically significant. The animals in the $\mathrm{AH} / \mathrm{F}(0) \mathrm{R}(50)$ group demonstrated significantly higher gastrocnemius weights than animals in the $\mathrm{AH} /$ vehicle group (21 vs. 16). For the rats in the $\mathrm{AH} / \mathrm{F}(0) \mathrm{R}(50)$ group, gastrocnemius weights were essentially identical to those for rats in the $\mathrm{AH} / \mathrm{F}(1) \mathrm{R}(0)$ group and slightly (but not statistically significantly) lower than gastrocnemius for rats in the $\mathrm{AH} / \mathrm{F}(1) \mathrm{R}(50)$ group (21 vs. 18 and 21 vs. 20).

\section{Discussion}

In the four Experiments, the observed effects of $\mathrm{AH}$-inoculation (with or without various treatments) on the heart and carcass weights were generally parallel to the effects on gastrocnemius muscle weights. AH-inoculation and treatment effects on the body and tissue weights are, therefore, general and not limited to the gastrocnemius muscle. Experimental uncertainty was 


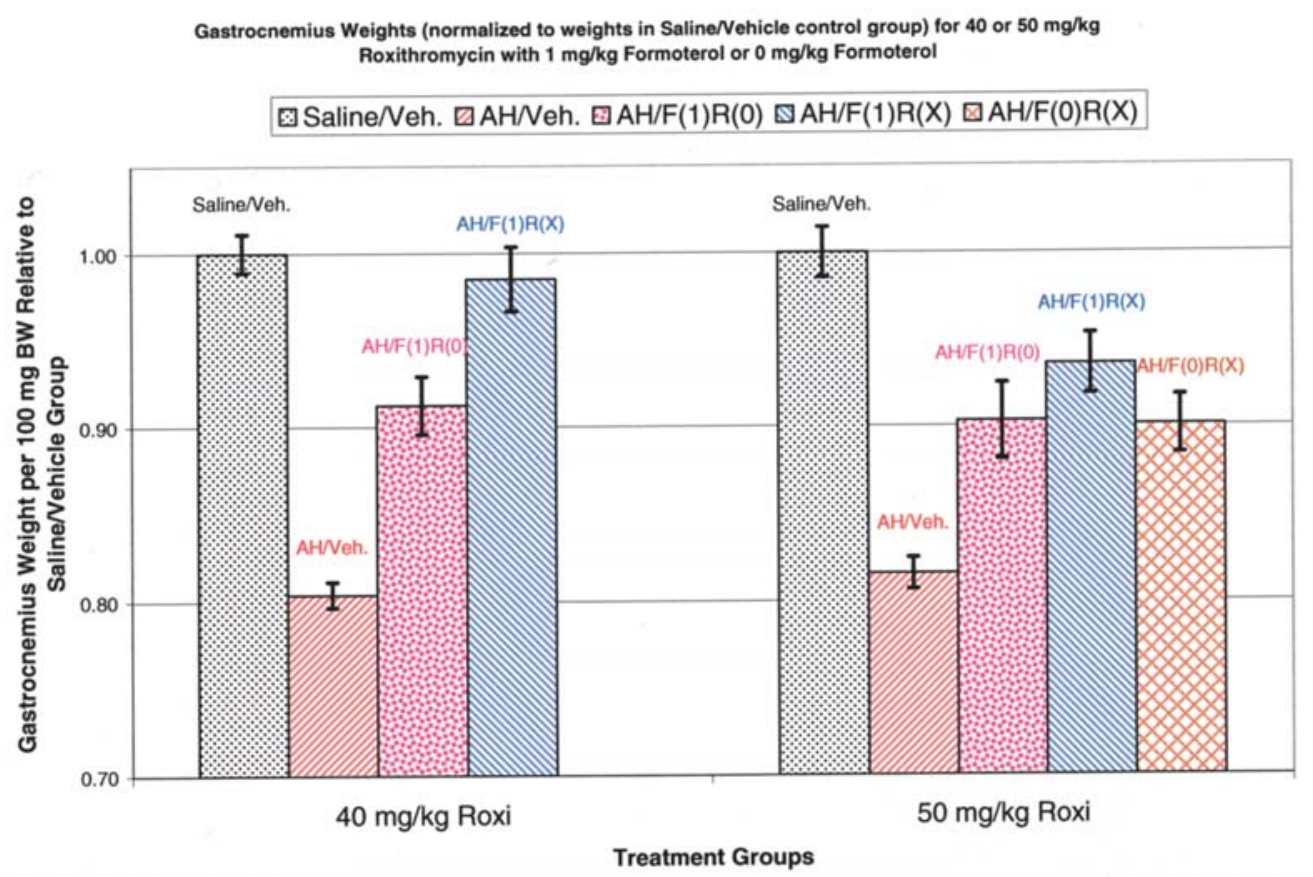

Figure 2. Gastrocnemius weights (mean $\pm \mathrm{SEM}$ ) for 40 or $50 \mathrm{mg} / \mathrm{kg}$ roxithromycin in $\mathrm{AH}$-inoculated rats.

Table X. Comparison of the gastrocnemius data with results reported by Busquets et al (30).

\begin{tabular}{|c|c|c|c|c|c|}
\hline \multirow[t]{2}{*}{ Inoculum/treatment ${ }^{\mathrm{a}}$} & \multicolumn{5}{|c|}{ Difference in mean gastrocnemius weights (g per $100 \mathrm{~g}$ of Day 5 body weight) } \\
\hline & Busquets & Experiment 1 & Experiment 2 & Experiment 3 & Experiment 4 \\
\hline $\mathrm{AH} /$ Vehicle - saline/vehicle & -0.088 & -0.086 & -0.078 & -0.105 & -0.102 \\
\hline $\mathrm{AH} / \mathrm{F}(1) \mathrm{R}(0)-\mathrm{AH} / \mathrm{vehicle}$ & 0.054 & 0.048 & 0.012 & 0.058 & 0.048 \\
\hline $\mathrm{AH} / \mathrm{F}(1) \mathrm{R}(0)$ - saline/vehicle & -0.038 & -0.038 & -0.066 & -0.047 & -0.054 \\
\hline
\end{tabular}

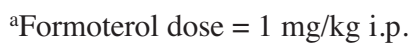

Table XI. The statistical significance of the difference in gastrocnemius weights in AH-inoculated rats receiving various treatments compared with gastrocnemius weights in $\mathrm{AH} /$ vehicle controls and in $\mathrm{AH} / \mathrm{F}(1) \mathrm{R}(0)$ controls. $^{\mathrm{a}}$

\begin{tabular}{lcccc}
\hline $\begin{array}{l}\text { Difference in weights } \\
\text { Formoterol (mg/kg) vs. roxithromycin (mg) }\end{array}$ & $\mathrm{AH} /$ treatment vs. AH/vehicle & \multicolumn{2}{c}{$\mathrm{AH} /$ treatment vs. AH/F(1)R(0) } \\
\hline $\mathrm{R}(5)$ & $\mathrm{F}(0)$ & $\mathrm{F}(1)$ & $\mathrm{F}(0)$ & $\mathrm{ns}$ \\
$\mathrm{R}(25)$ & $\mathrm{ns}$ & $\mathrm{ns}$ & $\mathrm{ns}$ \\
$\mathrm{R}(40)$ & not tested & $\mathrm{ns}$ tested & $\mathrm{ns}$ \\
$\mathrm{R}(50)$ & not tested & $\mathrm{p}<0.001$ & not tested & $\mathrm{p}<0.05$ \\
\hline
\end{tabular}

${ }^{\mathrm{a}} \mathrm{ns}$, not significant at $\mathrm{p}=0.05$.

lower for measurements of the gastrocnemius weight than for the heart and carcass weights. Therefore, the following sections focus on gastrocnemius data.

Fig. 1 demonstrates the reproducibility of the rat AH model with respect to gastrocnemius muscle weights (normalized to the gastrocnemius weights for the saline/vehicle groups in each Experiment). For the four Experiments, gastrocnemius muscle loss in AH/vehicle groups was measured as 15-20\% compared to the muscle weight in the saline/vehicle groups at Day 5. In the $\mathrm{AH} / \mathrm{F}(1) \mathrm{R}(0)$ groups, gastrocnemius muscle loss was measured as only $\sim 10 \%$ of the muscle mass in the saline/ vehicle groups. The variability in response to $\mathrm{AH}$-inoculation with either the vehicle or $1 \mathrm{mg} / \mathrm{kg}$ formoterol fumarate treatment probably reflects the highly aggressive nature of 
the model and the fact that there is a very steep drop in muscle mass over the relatively short (5 day) course of each Experiment.

It is therefore useful to compare the gastrocnemius muscle data from Experiments 1-4 with the data reported by Busquets et al (30) for the same rat AH model.

Table $\mathrm{X}$ shows that the changes in the gastrocnemius weights among the groups from Experiments 1-4 are identical in direction (positive or negative differences) and very similar in magnitude to the data reported by Busquets et al (30), thereby confirming the general conclusions of this report.

In the saline-inoculated rats, none of the investigated treatments demonstrated statistically significant effects on the gastrocnemius weights. Animals in the saline/F(1)R(0) group (Group 10, Experiment 2), had greater gastrocnemius muscle weights than those in the saline/vehicle control group (Group 6), consistent with literature reports (15) on the anticatabolic activity of formoterol.

In the AH-inoculated rats, the treatment group effects on gastrocnemius weights can be compared to the AH/vehicle control group and to the $\mathrm{AH} / \mathrm{F}(1) \mathrm{R}(0)$ control groups.

Table XI is a grid of the treatment groups $(0 \mathrm{mg} / \mathrm{kg}$ formoterol fumarate versus $5,25,40$ or $50 \mathrm{mg} / \mathrm{kg}$ roxithromycin and $1 \mathrm{mg} / \mathrm{kg}$ formoterol fumarate versus 5, 25, 40 or $50 \mathrm{mg} / \mathrm{kg}$ roxithromycin). The table shows the degree to which the gastrocnemius weight differences between the treatment and control (either $\mathrm{AH} /$ vehicle or $\mathrm{AH} / \mathrm{F}(1) \mathrm{R}(0)$ ) groups achieved statistical significance.

With respect to the gastrocnemius data in $\mathrm{AH}$-inoculated rats, the treatment groups receiving 5 or $25 \mathrm{mg} / \mathrm{kg}$ roxithromycin (either alone or in combination with $1 \mathrm{mg} / \mathrm{kg}$ formoterol fumarate) did not differ significantly from the control groups. The AH/F(1)R(40) treatment group was statistically significantly different from either the AH/vehicle or the $\mathrm{AH} / \mathrm{F}(1) \mathrm{R}(0)$ control group. The $\mathrm{AH} / \mathrm{F}(0) \mathrm{R}(50)$ treatment group was statistically significantly different from the AH/vehicle but essentially identical to the $\mathrm{AH} / \mathrm{F}(1) \mathrm{R}(0)$ control group. The $\mathrm{AH} / \mathrm{F}(1) \mathrm{R}(50)$ treatment group was statistically significantly different compared with the AH/vehicle control group but not with the $\mathrm{AH} / \mathrm{F}(1) \mathrm{R}(0)$ control group, although the $\mathrm{AH} / \mathrm{F}(1) \mathrm{R}(50)$ group had a somewhat higher gastrocnemius muscle mass than the $\mathrm{AH} / \mathrm{F}(1) \mathrm{R}(0)$ control group.

Fig. 2 shows that the combination of $40 \mathrm{mg} / \mathrm{kg}$ roxithromycin with $1 \mathrm{mg} / \mathrm{kg}$ formoterol fumarate prevented muscle loss significantly better than did $1 \mathrm{mg} / \mathrm{kg}$ formoterol alone. Similarly, the muscle loss was lower for the combination of $50 \mathrm{mg} / \mathrm{kg}$ roxithromycin plus $1 \mathrm{mg} / \mathrm{kg}$ formoterol fumarate than for either $50 \mathrm{mg} / \mathrm{kg}$ roxithromycin or $1 \mathrm{mg} / \mathrm{kg}$ formoterol fumarate administered individually. The differences in the gastrocnemius weights between the $\mathrm{AH} / \mathrm{F}(1) \mathrm{R}(50)$ group and either the $\mathrm{AH} / \mathrm{F}(1) \mathrm{R}(0)$ or the $\mathrm{AH} / \mathrm{F}(0) \mathrm{R}(50)$ group, however, did not achieve statistical significance.

In conclusion, herein we reported a novel observation that roxithromycin exerts anti-cachectic effects in the rat AH model. Roxithromycin administered at $50 \mathrm{mg} / \mathrm{kg}$ alone was just as effective as $1 \mathrm{mg} / \mathrm{kg}$ formoterol fumarate in preventing $\mathrm{AH}$ induced gastrocnemius muscle loss. Although the data in this report cannot conclusively establish any mechanism(s) for the roxithromycin effect on cachexia, the suppression of proinflammatory cytokines is the most likely explanation (42-50).
The anti-cachectic activity of formoterol fumarate shown here is consistent with literature reports (30-34) and with a mechanism involving the formoterol fumarate inhibition of proteolysis via the ubiquitin-proteasome pathway. The data reported here suggest that roxithromycin and formoterol fumarate work via independent mechanisms to antagonize cachexia in the AH rat model. It could, therefore, be concluded that the co-administration of formoterol fumarate and roxithromycin may offer the promise of an effective, multimodal treatment approach to the treatment of CACS.

\section{References}

1. Yavuzsen T, Davis MP, Walsh D, et al: Systematic review of the treatment of cancer-associated anorexia and weight loss. J Clin Oncol 23: 8500-8511, 2005.

2. Baracos V, MacDonald N, Clandinin MT, et al: Issues in palliative care: anorexia/cachexia syndrome in cancer identification of needs, gaps, and opportunities in Canadian research. Univ. Alberta Dept. of Oncol., Report for Canada Inst. Cancer Res., 2003.

3. Argiles JM, Meijsing SH, Pallares-Trujillo J, et al: Cancer cachexia: a therapeutic approach. Med Res Rev 21: 83-101, 2001.

4. Rubin H: Cancer cachexia: its correlations and causes. Proc Natl Acad Sci USA 100: 5384-5389, 2003.

5. Jatoi A Jr and Loprinzi CL: Current management of cancerassociated anorexia and weight loss. Oncology 15: 497-510, 2001.

6. Finley JP: Management of cancer cachexia. AACN Clin Issues 11: 590-603, 2000.

7. Nelson KA, Walsh D and Sheehan FA: The cancer anorexiacachexia syndrome. J Clin Oncol 12: 213-225, 1994.

8. Martignoni ME, Kunze P and Friess H: Cancer cachexia. Mol Cancer 2: 36, 2003.

9. Barber MD, Ross JA and Fearon KC: Cancer cachexia. Surg Oncol 8: 133-141, 1999.

10. Kotler DP: Cachexia. Ann Intern Med 133: 622-634, 2000.

11. Tisdale MJ: Cancer cachexia. Langenbecks Arch Surg 389: 299-305, 2004.

12. Chamberlain JS: Cachexia in cancer - zeroing in on myosin. $\mathrm{N}$ Engl J Med 351: 2124-2125, 2004.

13. Body JJ: The syndrome of anorexia-cachexia. Curr Opin Oncol 11: 255-260, 1999.

14. Gagnon B and Bruera E: A review of the drug treatment of cachexia associated with cancer. Drugs 55: 675-688, 1998.

15. Muscaritoli M, Bossola M, Aversa Z, Bellantone R and Rossi Fanelli F: Prevention and treatment of cancer cachexia: New insights into an old problem. Eur J Cancer 42: 31-41, 2006.

16. Dewys WD, Begg C, Lavin PT, et al: Prognostic effect of weight loss prior to chemotherapy in cancer patients. Eastern Cooperative Oncology Group. Am J Med 69: 491-497, 1980.

17. Argiles JM and Lopez-Soriano FJ: The role of cytokines in cancer cachexia. Med Res Rev 19: 223-248, 1999.

18. Tracey KJ, Wei H, Manogue KR, et al: Cachectin/tumor necrosis factor induces cachexia, anemia, and inflammation. J Exp Med 167: 1211-1227, 1988.

19. Moldawer LL, Georgieff M and Lundholm K: Interleukin 1, tumour necrosis factor-alpha (cachectin) and the pathogenesis of cancer cachexia. Clin Physiol 7: 263-274, 1987.

20. Moldawer LL, Rogy MA and Lowry SF: The role of cytokines in cancer cachexia. J Parenter Enteral Nutr 16: 43S-49S, 1992.

21. Mantovani G, Maccio A, Lai P, et al: Cytokine involvement in cancer anorexia/cachexia: role of megestrol acetate and medroxyprogesterone acetate on cytokine down-regulation and improvement of clinical symptoms. Crit Rev Oncog 9: 99-106, 1998.

22. Mitch WE and Goldberg AL: Mechanisms of muscle wasting. The role of the ubiquitin-proteasome pathway. $\mathrm{N}$ Engl J Med 335: 1897-1905, 1996

23. Costelli P and Baccino FM: Mechanisms of skeletal muscle depletion in wasting syndromes: role of ATP-ubiquitindependent proteolysis. Curr Opin Clin Nutr Metab Care 6: 407-412, 2003.

24. Ding X, Price SR, Bailey JL, et al: Cellular mechanisms controlling protein degradation in catabolic states. Miner Electrolyte Metab 23: 194-197, 1997. 
25. Price SR, Du JD, Bailey JL, et al: Molecular mechanisms regulating protein turnover in muscle. Am $\mathrm{J}$ Kidney Dis 37: S112-S114, 2001.

26. Lecker SH, Solomon V, Mitch WE, et al: Muscle protein breakdown and the critical role of the ubiquitin-proteasome pathway in normal and disease states. J Nutr 129: 227S-237S, 1999.

27. Lecker SH, Solomon V, Price SR, et al: Ubiquitin conjugation by the N-end rule pathway and mRNAs for its components increase in muscles of diabetic rats. J Clin Invest 104: 1411-1420, 1999.

28. Acharyya S, Ladner KJ, Nelsen LL, et al: Cancer cachexia is regulated by selective targeting of skeletal muscle gene products. J Clin Invest 114: 370-378, 2004.

29. Lelli G, Montanari M, Gilli G, et al: Treatment of the cancer anorexia-cachexia syndrome: a critical reappraisal. J Chemother 15: 220-225, 2003

30. Busquets S, Figueras MT, Fuster G, et al: Anticachectic effects of formoterol: a drug for potential treatment of muscle wasting. Cancer Res 64: 6725-6731, 2004.

31. Costelli P, Garcia-Martinez C, Llovera M, et al: Muscle protein waste in tumor-bearing rats is effectively antagonized by a beta 2-adrenergic agonist (clenbuterol). Role of the ATP-ubiquitindependent proteolytic pathway. J Clin Invest 95: 2367-2372, 1995.

32. Costelli P, Bossola M, Muscaritoli M, et al: Anticytokine treatment prevents the increase in the activity of ATP-ubiquitinand $\mathrm{Ca}\left(2^{+}\right)$-dependent proteolytic systems in the muscle of tumour-bearing rats. Cytokine 19: 1-5, 2002.

33. Tessitore L, Bonelli G and Baccino FM: Early development of protein metabolic perturbations in the liver and skeletal muscle of tumour-bearing rats. A model system for cancer cachexia. Biochem J 241: 153-159, 1987.

34. Carbo N, Lopez-Soriano J, Tarrago T, et al: Comparative effects of beta2-adrenergic agonists on muscle waste associated with tumour growth. Cancer Lett 115: 113-118, 1997.

35. Mackenzie ML, Bedard N, Wing SS, et al: A proinflammatory tumor that activates protein degradation sensitizes rats to catabolic effects of endotoxin. Am J Physiol Endocrinol Metab 289: E527-E533, 2005.

36. DeJong CH, Busquets S, Moses AG, et al: Systemic inflammation correlates with increased expression of skeletal muscle ubiquitin but not uncoupling proteins in cancer cachexia. Oncol Rep 14: 257-263, 2005

37. Busquets S, Garcia-Martinez C, Olivan M, et al: Overexpression of UCP3 in both murine and human myotubes is linked with the activation of proteolytic systems: A role in muscle wasting? Biochim Biophys Acta 1760: 253-258, 2006.

38. Klaude M, Hammarqvist F and Wemerman J: An assay of microsomal membrane-associated proteasomes demonstrates increased proteolytic activity in skeletal muscle of intensive care unit patients. Clin Nutr 24: 259-265, 2005.

39. Bossola M, Muscaritoli M, Costelli P, et al: Increased muscle ubiquitin mRNA levels in gastric cancer patients. Am J Physiol Regul Integr Comp Physiol 280: R1518-R1523, 2001.

40. Bossola M, Muscaritoli M, Costelli P, et al: Increased muscle proteasome activity correlates with disease severity in gastric cancer patients. Ann Surg 237: 384-389, 2003.

41. Bossola M, Muscaritoli M, Costelli P, et al: Muscle ubiquitin m-rNA levels in patients with end-stage renal disease on maintenance hemodialysis. J Nephrol 15: 552-557, 2002.

42. Piffar PM, Fernandez R, Tchaikovski O, et al: Naproxen, clenbuterol and insulin administration ameliorates cancer cachexia and reduce tumor growth in Walker 256 tumor-bearing rats. Cancer Lett 201: 139-148, 2003.

43. Amsden GW: Anti-inflammatory effects of macrolides - an underappreciated benefit in the treatment of community-acquired respiratory tract infections and chronic inflammatory pulmonary conditions? J Antimicrob Chemother 55: 10-21, 2005.
44. Siddiqui J: Immunomodulatory effects of macrolides: implications for practicing clinicians. Am J Med 117: 26S-29S, 2004.

45. Labro MT: Cellular and molecular effects of macrolides on leukocyte function. Curr Pharm Des 10: 3067-3080, 2004.

46. Tamaoki J, Kadota J and Takizawa H: Clinical implications of the immunomodulatory effects of macrolides. Am J Med 117: 5S-11S, 2004.

47. Zalewska-Kaszubska J and Gorska D: Anti-inflammatory capabilities of macrolides. Pharmacol Res 44: 451-454, 2001.

48. Scaglione F and Rossoni G: Comparative anti-inflammatory effects of roxithromycin, azithromycin and clarithromycin. J Antimicrob Chemother 41: 47-50, 1998.

49. Suzaki H, Asano K, Ohki S, Kanai K, Mizutani T and Hisamitsu T: Suppressive activity of a macrolide antibiotic, roxithromycin, on pro-inflammatory cytokine production in vitro and in vivo. Mediators Inflamm 8: 199-204, 1999.

50. Ianaro A, Ialenti A, Maffia P, et al: Anti-inflammatory activity of macrolide antibiotics. J Pharmacol Exp Ther 292: 156-163, 2000.

51. Agen C, Danesi R, Blandizzi C, et al: Macrolide antibiotics as anti-inflammatory agents: roxithromycin in an unexpected role. Agents Actions 38: 85-90, 1993.

52. Konno S, Adachi M, Asano K, et al: Influences of roxithromycin on cell-mediated immune responses. Life Sci 51: PL107PL112, 1992.

53. Konno S, Adachi M, Asano $\mathrm{K}$, et al: Inhibition of human $\mathrm{T}$ lymphocyte activation by macrolide antibiotic, roxithromycin. Life Sci 51: PL231-PL236, 1992.

54. Konno S, Asano K, Kurokawa M, et al: Antiasthmatic activity of a macrolide antibiotic, roxithromycin: analysis of possible mechanisms in vitro and in vivo. Int Arch Allergy Immunol 105 308-316, 1994.

55. Sakito O, Kadota J, Kohno S, et al: Interleukin 1 beta, tumor necrosis factor alpha, and interleukin 8 in bronchoalveolar lavage fluid of patients with diffuse panbronchiolitis: a potential mechanism of macrolide therapy. Respiration 63: 42-48, 1996.

56. Desaki M, Okazaki H, Sunazuka T, et al: Molecular mechanisms of anti-inflammatory action of erythromycin in human bronchial epithelial cells: possible role in the signaling pathway that regulates nuclear factor-kappaB activation. Antimicrob Agents Chemother 48: 1581-1585, 2004.

57. Ueno S, Aoki D, Kubo F, et al: Roxithromycin inhibits constitutive activation of nuclear factor $\{$ kappa $\} \mathrm{B}$ by diminishing oxidative stress in a rat model of hepatocellular carcinoma. Clin Cancer Res 11: 5645-5650, 2005.

58. Kim YS and Sainz RD: Beta-adrenergic agonists and hypertrophy of skeletal muscles. Life Sci 50: 397-407, 1992.

59. Ryall JG, Gregorevic P, Plant DR, et al: Beta 2-agonist fenoterol has greater effects on contractile function of rat skeletal muscles than clenbuterol. Am J Physiol Regul Integr Comp Physiol 283: R1386-R1394, 2002.

60. Choo JJ, Horan MA, Little RA, et al: Anabolic effects of clenbuterol on skeletal muscle are mediated by beta 2 -adrenoceptor activation. Am J Physiol 263: E50-E56, 1992.

61. Maltin CA, Delday MI, Watson JS, et al: Clenbuterol, a betaadrenoceptor agonist, increases relative muscle strength in orthopaedic patients. Clin Sci 84: 651-654, 1993.

62. Emery PW, Rothwell NJ, Stock MJ, et al: Chronic effects of beta 2 -adrenergic agonists on body composition and protein synthesis in the rat. Biosci Rep 4: 83-91, 1984.

63. Lambert CP, Uc EY and Evans WJ: Beta-2 adrenergic agonists in the treatment of muscular atrophy. In: Pharmacotherapy of Cachexia. Hofbauer KG, Anker SD, Inui A and Nicholson JR (eds). CRC Press (Taylor and Francis), Boca Raton, pp311-325, 2006. 